\title{
Peningkatan Derajat Kesehatan Mental melalui Terapi Aktivitas Kelompok dalam Posyandu Jiwa
}

\author{
Desak Made Ari Dwi Jayanti ${ }^{1^{*}}$, R. Tri Rahyuning Lestari ${ }^{2}$, Ni Kadek Yuni \\ Lestari $^{3}$, Ni Made Nopita Wati ${ }^{4}$, I Gede Juana Masta ${ }^{5}$ \\ 1,2,3,4,5 STIKes Wira Medika Bali \\ *Email : djdesak@gmail.com
}

\begin{abstract}
Background: This community service activity aims to improve mental health by applying group activity therapy in the posyandu. Of the soul. Methods: Used is learning method by finding various information related to group activity therapy (TAK). The role play method is by practicing directly how the implementation of TAK is in accordance with their respective roles so that it can be demonstrated directly by the patient and what he wants to convey in the TAK can be properly addressed to the patient. Results: The problem faced at this time is the lack of community knowledge in this case the family in caring for people with mental disorders ODGJ and how treatment can be provided through TAK. Conclusions: Problem solving that can be done is to provide assistance in providing knowledge, understanding and implementing role play so that it can be applied in everyday life and improve mental health.
\end{abstract}

Keywords: mental health, TAK, soul of posyandu, role play

\section{PENDAHULUAN}

Terjadinya gangguan jiwa akibat koping individu yang tidak baik. Menurut Keliat, dkk, (2013), adanya ketidak mampuan dan hambatan dalam berhubungan sosial merupakan salah satu dari tanda dan gejala dari gangguan jiwa yang menyebabkan suatu penderitaan bagi orang tersebut. Adanya perubahan dalam pikiran, perasaan dan perilaku yang menyebabkan seseorang mengalami gangguan jiwa yang lebih sering disebut Orang dengan Gagguan Jiwa (ODGJ). Gangguan jiwa apabila tidak ditangani akan menyebabkan kondisi yang lebih buruk sampai tidak memperhatikan dirinya sendiri (Riskesdas, 2013). Ada berbagai faktor yang menyebabkan gangguan jiwa diantaranya psikis, sosial dan lingkungan dimana disertai dengan berbagai gejala meliputi halusinasi, waham, delusi, isolasi sosial, harga diri rendah, perilaku kekerasan dan bahkan sampai mengalami defisit perawatan diri (Maramis, 2009).

Kejadian skizofreni di dunia menurut WHO pada tahun 2016 yaitu sejumlah 21 juta jiwa. Lebih dari 50\% pasien tidak mendapatkan perawatan yang tepat. Data Riset Kesehatan Dasar (2018) menunjukkan di Indonesia anggota keluarga dengan gangguan jiwa skizofrenia mengalami peningkatan, data tahun 2013 sejumlah 1,7 permil dan 2018 menjadi 7 permil. Bali yang mulanya menempati urutan ke tiga menjadi menempati urutan pertama dengan data tahun 2013 sejumlah 2,3 permil dan 2018 menjadi 11 permil. Puskesmas Sukawati II merupakan salah satu puskesmas yang mengembangkan pelayanan kesehatan jiwa berbasis masyarakat dengan menjalankan program posyandu jiwa. Jumlah pasien ODGJ di wilayah kerja puskesmas sukawati sejumlah 98 orang dimana salah satu wilayah kerjanya ada di Desa Batubulan Kangin. Berdasarkan kejadian tersebut maka perlu dilakukan kegiatan untuk mendukung program kesehatan jiwa yang 
berbasis masyarakat, salah satu diantaranya adalah pelaksaan posyandu jiwa. Salah satu upaya yang bisa diberikan dalam posyadu jiwa dari keperawatannya dengan memberikan terapi aktivitas kelompok. Melalui terapi aktivitas kelompok akan dapat meningkatkan kemampuan sosialisasi ODGJ sehingga bisa kembali lagi kedalam kehidupan bermasyarakat yang akan di laksanakan di Wilayah Kerja Puskesmas Sukawati II di Desa Batubulan Kangin. Adapun tujuan dilakukan pengabdian masyarakat ini secara umum adalah untuk meningkatkan derajat kesehatan jiwa melalui terapi aktivitas kelompok di dalam posyandu jiwa, dan secara khusus dapat meningkatkan kemampuan ODGJ dalam bersosialisasi, meningkatkan dukungan keluarga, meningkatkan pemahaman kader dalam melaksanakan TAK, dan pelaksanaan kegiatan TAK dalam diterapkan di kegiatan rutin posyandu jiwa.

\section{TINJAUAN PUSTAKA}

\subsection{Posyandu Jiwa}

Posyandu kesehatan jiwa adalah salah satu program untuk mendukung kesehatan jiwa. Tujuan posyandu jiwa adalah meningkatkan derajat kesehatan yang sehat agar tetap sehat, yang beresiko tidak menjadi sakit dan yang sakit menjadi sehat dan tentunya akan dapat meningkatkan kemampuan masyarakat dalam mengenal masalah kesehatan jiwa, sehingga stigma dapat dihapuskan (Keliat, 2019).

Pelaksanaan posyandu jiwa mengaju pada lima meja diantaranya adalah meja 1 adalah untuk mengidentifikasi data awal meliputi nama, tanggal, nomur regitrasi, jenis kelamin, usia dan alamat. Data-data ini biasanya di isi oleh kader kesehatan jiwa. Meja 2 bertugas melakukan penimbangan dan pengukuran berat dan tinggi badan oleh kader posyandu jiwa. Pendokumentasian dilakukan pada kartu menuju sehat jiwa (KMSJ). Meja 3 adalah meja yang bertugas mengidentifikasi tanda dan gejala yang dirasakan oleh ODMK atau ODGJ. Pencatatan dilakukan oleh kader posyandu jiwa dan didokumentasikan dalam KMSJ. Meja IV (Penilaian dan Pelatihan Kemandirian dan Produktifitas ODMK dan ODGJ). Meja 4 memberikan layanan berupa identifikasi tingkat kemandirian dan produktifitas ODGJ oleh kader posyandu jiwa. Hasil identifikasi digunakan untuk melakukan pelatihan ketrampilan hidup sehari-hari, perawatan diri serta peningkatan hubungan dan komunikasi ODMK dan ODGJ oleh Kader posyandu jiwa. Meja 5 berfokus pada pemberian pelayanan kesehatan jiwa oleh petugas Kesehatan. Adapun pelayanan kesehatan yang diberikan diantaranya meliputi pemberian vitamin, penambahan nutrisi, pemantauan psikofarmaka, dan konsultasi kesehatan jiwa atau pedidikan kesehatan jiwa bagi klien dan keluarga (Keliat, 2019).

\subsection{Terapi Ativitas Kelompok (TAK)}

Terapi Aktifitas Kelompok merupakan suatu terapi yang dilakukan secara berkelompok sehingga ODGJ dapat dilatih kembali kemampuan sosialnya sehingga bisa kembali kedalam kehidupan bermasyarakat. Pasien juga dapat saling berbagi 
pengalaman untuk menyelesaikan permasalahan yang dihadapi (Keliat \& Parwirowiyono, 2019). Secara umum TAK memiliki manfaat untuk meningkatkan kemampuan komunikasi pasien dimana akan ada interaksi lebih dari 2 orang. Meningkatkan kemampuan sosialisasi dan adaptasi. Meningkatkan kemampuan psikologis dan tentunya memiliki fungsi rehabilitative dimana dapat meningkatkan kemampuan sosial, ekspresi diri dan kemampuan dalam menghadapi permasalahan yang terjadi dalam kehidupan sehari hari (Keliat \& Parwirowiyono, 2019).

\section{METODE}

Adapun metode yang dipakai untuk menunjang pelaksanaan pengabdian masyarakat adalah:

\section{a. Metode Pengumpulan Data}

Data awal dikumpulkan melalui wawancara dengan pemegang program jiwa dan mencatat data di rekam medis pada Puskesmas Sukawati II.

\section{b. Menentukan Tema}

Tema ditentukan berdasarkan hasil wawancara dan data yang ada pada rekam medis, bahwa ternyata TAK belum pernah dilakukan dan pasien belum pernah dilatih dalam kegiatan berkelompok. Membuat canang dipilih karena pasien banyak yang memiliki kemampuan dalam menjarit janur.

c. Mencari Studi Pustaka

Studi Pustaka dilakukan dengan mencari buku tentang Kesehatan Jiwa, tentang TAK dan jurnal terkait yang membahas TAK dan Posyandu Jiwa.

\section{d. Membuat Materi dan Merancang TAK}

Membuat Proposal Pengabdian Masyarakat dan menyiapkan peralatan yang diperlukan dalam TAK membuat canang

e. Melakukan Roleplay

TAK dipimpin oleh leader dan dibantu oleh co leader, fasilitator dan observer sesuai dengan apa yang direncanakan pada proposal. Role play dilakukan selama 30 menit.

\section{HASIL}

Hasil penelitian ini diawali dengan data distribusi jumlah penduduk sebagai berikut: Tabel 1. Distribusi Jumlah Penduduk

\begin{tabular}{lc}
\hline Wilayah & Jumlah Penduduk (Jiwa) \\
\hline Singapadu Kaler & 5.537 \\
Singapadu Tengah & 4.763 \\
Singapadu & 5.878 \\
Celuk & 4.113 \\
Batubulan & 17.361 \\
Batubulan Kangin & 7.949 \\
\hline \multicolumn{2}{c}{ Tabel 1 menunjukkan bahwa penduduk wilayah Batubulan memiliki jumlah } \\
penduduk tertinggi.
\end{tabular}


Tabel 2. Distribusi Sebaran ODGJ

\begin{tabular}{lcc}
\hline ODGJ & Jumlah (orang) & Persentase (\%) \\
\hline Skizofrenia & 64 & 70 \\
Psikosa & 28 & 30 \\
\hline Total & 92 & 100 \\
\hline Jenis Kelamin & & \\
\hline Laki-laki & 55 & 59,79 \\
Perempuan & 37 & 40,21 \\
\hline Total & 92 & 100 \\
\hline
\end{tabular}

Tabel 3. Karakteristik Keluarga Pasien yang Merawat ODGJ

\begin{tabular}{lcc}
\hline \multicolumn{1}{c}{ Karakteritik Responden } & Frekuensi (F) & Persentase (\%) \\
\hline Umur Responden & & \\
26-35 tahun (Dewasa Awal) & 30 & 6,7 \\
36-45 tahun (Dewasa Akhir) & 22 & 50,0 \\
$46-55$ tahun (Lansia Awal) & 4 & 36,6 \\
56-65 tahun (Lansia Akhir) & 60 & 6,7 \\
\hline Total & & 100 \\
\hline Jenis Kelamin & 24 & \\
Laki-Laki & 36 & 40,0 \\
Perempuan & 60 & 60,0 \\
\hline Total & & 100 \\
\hline Tingkat Pendidikan & 2 & \\
Tidak Sekolah & 21 & 3,3 \\
SD & 12 & 35,0 \\
SLTP & 25 & 20,0 \\
SLTA & 60 & 41,7 \\
\hline Total & & 100 \\
\hline Pekerjaan & 17 & \\
Pegawai Swasta/ Wiraswasta & 18 & 28,3 \\
Buruh/Petani/Pedagang & 25 & 30,0 \\
Tidak Bekerja & 60 & 41,7 \\
\hline Total & & 100 \\
\hline Hubungan Dengan Pasien & 16 & 26,7 \\
Orang Tua Kandung & 25 & 41,7 \\
Suami/Istri & 4 & 100 \\
Paman/Bibi & 60 & \\
Saudara Kandung & & \\
\hline Total & 55 & \\
\hline
\end{tabular}


Tabel 4. Gambaran Dukungan Keluarga yang Merawat

\begin{tabular}{|c|c|c|c|c|c|c|c|c|}
\hline \multirow{3}{*}{$\begin{array}{c}\text { Indikator Dukungan } \\
\text { Keluarga }\end{array}$} & \multicolumn{6}{|c|}{ Kategori } & \multirow{2}{*}{\multicolumn{2}{|c|}{ Total }} \\
\hline & \multicolumn{2}{|c|}{ Rendah } & \multicolumn{2}{|c|}{ Sedang } & \multicolumn{2}{|c|}{ Tinggi } & & \\
\hline & $\mathbf{F}$ & $\%$ & $\mathbf{F}$ & $\%$ & $\mathbf{F}$ & $\%$ & $\mathbf{F}$ & $\%$ \\
\hline Dukungan Emosional & 0 & 0 & 17 & 28,3 & 43 & 71,7 & 60 & 100 \\
\hline Dukungan Instrumental & 0 & 0 & 13 & 21,7 & 47 & 78,3 & 60 & 100 \\
\hline Dukungan Informasi & 0 & 0 & 40 & 66,7 & 20 & 33,3 & 60 & 100 \\
\hline Dukungan Penghargaan & 0 & 0 & 29 & 48,3 & 31 & 51,7 & 60 & 100 \\
\hline
\end{tabular}

Tabel 5. Karakteristik Dukungan Keluarga

\begin{tabular}{lcc}
\hline Dukungan Keluarga & Frekuensi (F) & Persentase (\%) \\
\hline Rendah & 0 & 0 \\
Sedang & 26 & 43.3 \\
Tinggi & 34 & 56.7 \\
\hline Total & 60 & 100 \\
\hline
\end{tabular}

Tabel 6. Karakteristik Kader Jiwa Panji Mas

\begin{tabular}{lcc}
\hline \multirow{2}{*}{ Jenis Kelamin } & \multicolumn{2}{c}{ Jumlah (Orang) } \\
\cline { 2 - 3 } & F & \% \\
\hline Laki-laki & 3 & 33,33 \\
Perempuan & 6 & 66,67 \\
\hline Jumlah & 9 & 100 \\
\hline
\end{tabular}

Tabel 7. Hasil Pelaksanaan TAK Membuat Canang

\begin{tabular}{|l|c|c|c|c|c|c|c|c|}
\hline \multirow{2}{*}{$\begin{array}{l}\text { Kemampuan } \\
\text { Membuat Canang }\end{array}$} & \multicolumn{3}{|c|}{ Sebelum kegiatan/ Pre-test } & \multicolumn{3}{c|}{$\begin{array}{c}\text { Setelah Kegiatan/ Post- } \\
\text { test }\end{array}$} \\
\cline { 2 - 10 } & \multicolumn{2}{|c|}{ Berhasil } & \multicolumn{2}{|c|}{$\begin{array}{c}\text { Tidak } \\
\text { Berhasil }\end{array}$} & \multicolumn{2}{c|}{ Berhasil } & \multicolumn{2}{|c|}{$\begin{array}{c}\text { Tidak } \\
\text { berhasil }\end{array}$} \\
\cline { 2 - 10 } & (F) & \% & (F) & \% & (F) & \% & (F) & \% \\
\hline $\begin{array}{l}\text { Menyebutkan alat } \\
\text { yang dibutuhkan } \\
\text { dalam membuat } \\
\text { canang }\end{array}$ & 5 & 83,33 & 1 & 16,67 & 6 & 100 & 0 & 0 \\
\hline $\begin{array}{l}\text { Menceritakan cara } \\
\text { membuat canang }\end{array}$ & 4 & 66,67 & 2 & 33,33 & 6 & 100 & 0 & 0 \\
\hline $\begin{array}{l}\text { Menyebutkan } \\
\text { manfaat dari canang }\end{array}$ & 4 & 66,67 & 2 & 33,33 & 6 & 100 & 0 & 0 \\
\hline $\begin{array}{l}\text { Mempraktekan cara } \\
\text { membuat canang }\end{array}$ & 5 & 83,33 & 1 & 16,67 & 6 & 100 & 0 & 0 \\
\hline $\begin{array}{l}\text { Menjelaskan } \\
\text { manfaat dan hasil } \\
\text { yang diperoleh jika } \\
\text { ahli dalam membuat } \\
\text { canang }\end{array}$ & 0 & 0 & 6 & 100 & 6 & 100 & 0 & 0 \\
\hline
\end{tabular}




\section{PEMBAHASAN}

Unit Pelayanan Teknis Puskesmas Sukawati II mewilayahi 6 (enam) Desa antara lain Singapadu Kaler memiliki 5 banjar, Singapadu Tengah memiliki 5 banjar, Singapadu memiliki 7 banjar, Celuk memiliki 3 banjar, Batubulan memiliki 13 banjar dan Batubulan Kangin memiliki 9 banjar. Total banjar di wilayah Puskesmas Sukawati II berjumlah 48 banjar dengan jumlah penduduk sebesar 45.621 jiwa. Sebaran ODGJ terbanyak dengan diagnosa medis skizofrenia sejumlah 64 orang $(0,69 \%)$ dan jumlah pasien lebih banyak dengan jenis kelamin laki-laki sejumlah 55 orang $(0,59 \%)$. Keluarga merupakan orang terdekat pasien dan tentunya menjadi jembatan utama dalam kesembuhan pasien, adapun karakteristik keluarga yang merawat pasien ODGJ terbanyak dengan kategori usia dewasa akhir sejumlah 30 orang $(50 \%)$, dimana keluarga terdekat yang langsung merawat pasien adalah perempuan sejumlah 36 orang $(60 \%)$. Tingkat Pendidikan keluarga terbanyak SLTA sejumlah 25 orang $(41,7 \%)$. Keluarga yang merawat langsung pasien dan dekat dengan pasien kebanyakan tidak bekerja sejumlah 25 orang $(41,7 \%)$ dimana hubungan dengan pasien dan keluarga yang merawat langsung pasien adalah sebagai istri/suami sejumlah 25 orang (41,7\%). Adapun gambaran dukungan keluarga yang merawat ODGJ terbagi dalam indikator dimana dukungan emosional terbanyak pada katerori tinggi sejumlah 43 orang $(71,7 \%)$, dukungan instrumental terbanyak pada kategori tinggi sejumlah 47 orang $(7,3 \%)$, dukungan informasi terbanyak pada kategori sedang sejumlah 40 orang $(66,7 \%)$ dan dukungan penghargaan terbanyak pada kategori tinggi sejumlah 31 orang $(51,7 \%)$. Dapat disimpulkan bahwa pada tabel 5 sebagian besar dukungan keluarga berada dalam kategori tinggi, yaitu sebanyak 34 orang $(56,7 \%)$.

Friedman, (2010) menjelaskan bahwa keterlibatan keluarga sangatlah membantu dalam proses penyembuhan pasien seperti dukungan emosional dimana dukungan ini memberi kasih sayang serta kenyamanan terhadap pasien, dukungan instrumental seperti bantuan materi ataupun fasilitas yang diperlukan pasien, dukungan informasi seperti pemberian informasi, serta dukungan penghargaan yaitu seperti pemberian motivasi atau semangat untuk pengobatan pasien. Dukungan keluarga yang tinggi dapat menunjukan bahwa keberhasilan keluarga di dalam pengobatan pasien dapat berjalan secara optimal, dimana diwujudkan dengan penerimaan keluarga terhadap keadaan yang dialami saat ini oleh pasien. Adianta \& Putra, (2017) menunjukan sebagian besar responden memiliki dukungan keluarga dalam kategori tinggi yaitu sebanyak 244 orang atau sekitar $(85,3 \%)$.

Susksesnya pelayanan kesehatan jiwa di komunitas khususnya dalam melaksanakan posyandu jiwa tidak terlepas dari peran kader. Adapun jumlah kader yang dimiliki sejumlah 9 orang dimana jumlah terbanyak berjenis kelamin perempuan 6 orang $(66,67 \%)$. Adanya kader ini juga akan membantu dalam pelaksanaan TAK di posyandu jiwa. Adapun TAK yang telah dilakukan adalah membuat canang. TAK ini dipilih sesuai dengan pengkajian awal yang telah dilakukan dimana kebanyakan pasien memiliki bakat membuat canang. Hasil yang di peroleh saat pre-test menunjukkan yang berhasil menyebutkan alat yang 
dibutuhkan dalam membuat canang sejumlah 83,33\%, yang berhasil menceritakan cara membuat canang sejumlah 66,67\%, yang berhasil menyebutkan manfaat dari canang sejumlah $66,67 \%$, yang berhasil mempraktekan cara membuat canang sejumlah $83,3 \%$ dan tidak ada yang mampu menjelaskan manfaat dan hasil yang diperoleh jika ahli dalam membuat canang. Adapun data post-test yang diperoleh adalah 100\% ODGJ mampu menyebutkan alat yang dibutuhkan dalam membuat canang, menceritakan cara membuat, menyebutkan manfaat dari canang, mempraktekan cara membuat canang dan menjelaskan manfaat dan hasil yang diperoleh jika ahli dalam membuat canang. Notoatmodjo (2012) menyebutkan pengetahuan diperoleh melalui media dan alat bantu yang digunakan, sehingga peneliti berpendapat terjadinya perubahan data dari pre-test ke post test akibat dari media dan alat bantu pembelajaran yang digunakan saat TAK. Data ini juga didukung oleh penelitian menurut Yuzuf,.er all (2007) bahwa terjadi perubahan data pre-test dan post-test dimana saat pre-test data yang ditunjukkan $100 \%$ pasien tidak bisa mengendalikan halusinasi, namun setelah post-test menunjukkan $100 \%$ pasien mamapu mengendalikan halusinasi. Penelitian lain juga menunjukkan terdapat perubahan data pre-tes ke post-test bahwa terjadi perubahan kemampuan berinteraksi pada pasien isoslasi sosial setelah diberikan TAK sosialisasi, dari tidak mampu menjadi mampu bersosialisasi.

\section{KESIMPULAN DAN SARAN}

\subsection{Kesimpulan} TAK.

Terdapat peningkatan kemampuan pasien membuat canang setelah dilakukan

\subsection{Saran}

Disarankan kepada Puskesmas Sukawati II Gianyar agar memasukkan kegiatan TAK kedalam posyandu jiwa, memberikan pelatihan kepada kader jiwa bagaimana melakukan TAK dan menggali potensi yang dimiliki oleh ODGJ sehingga bisa mengembangkan pelatihan yang tepat bagi ODGJ.

\section{UCAPAN TERIMA KASIH}

Ucapan terimakasih disampaikan kepada Kepala Puskesmas Sukawati II, pemegang program jiwa dan kader jiwa, keluarga dan pasien (ODGJ) yang telah terlibat dan berperan aktif dalam kegiatan TAK. LPPM STIKes Wira Medika yang telah mendanai kegiatan ini sehingga bisa berjalan dengan baik. Mahasiswa dan mahasiswi dan teman dosen yang telah banyak membantu dalam kegiatan pengabdian masyarakat ini sehingga bisa terlaksana dengan baik.

\section{DAFTAR RUJUKAN}

Adianta, I. K. A., \& Putra, I. M. S. (2017). Hubungan Dukungan Keluarga Dengan Tingkat Kepatuhan Minum Obat Pada Pasien Skizofrenia. Jurnal Riset Kesehatan Nasional, 1(1), 1-7 
Barbara, K. (2010). Fundamental Keperawatan. Jakarta : EGC

Dinas Kesehatan Kota Madiun. (2007). Buku Pegangan Kader Desa Siaga Kota Madiun.Madiun.Hal. 1-54

Friedman, M. (2010). Buku Ajar Keperawatan Keluarga Riset, Teori dan Praktik. Edisi 5. Jakarta: EGC.

Hastutiningtyas dan Setyabudi. (2016). Peran terapi aktivitas kelompok sosialisasi (taks) terhadap kemampuan interaksi sosial dan masalah isolasi sosial pasien. Jurnal Care Vol. 4, No.3, Tahun 2016. file://C:/Users/okaar/Downloads/435747-1-SM.pdf

Keliat \& Parwirowiyono. (2019). Keperawatan Jiwa Terapi Aktivitas Kelompok. Jakarta: EGC

Keliat, A. (2019). Posyandu Kesehatan Jiwa. Jakarta: EGC

Keliat, B.A, dkk. (2013). Keperawatan Kesehatan Jiwa Komunitas: CMHN (Basic Course). Jakarta: EGC.

Riset Kesehatan Dasar. (2018). Laporan Badan Penelitian dan Pengembangan Kesehatan, Departemen Kesehatan Republik Indonesia

Riset Kesehatan Dasar. (2013). Laporan Badan Penelitian dan Pengembangan Kesehatan, Departemen Kesehatan Republik Indonesia

Notoatmodjo,S. (2012). Metodologi Penelitian Kesehatan. Jakarta: Rineka Cipta.

Yususf, Rizki.F, Nursalam, Iskandar. (2007). Terapi Aktifitas Kelompok (Tak): Stimulasi Persepsi Modifikasi Sebagai Alternatif Pengendalian Halusinasi Dengar Pada Klien Skizofrenia. Jurnal Ners. Vol. 2 No. 1 Mei-September 2007. file:///C:/Users/okaar/Downloads/4948-14375-1-SM\%20(1).pdf 